\title{
Distraction Lengthening of First Metacarpal in Traumatic Thumb Amputations
}

\author{
Abid Saleem ${ }^{1}$ Ramesh Kumar Sharma ${ }^{2}$ Parmod Kumar ${ }^{2}$ \\ ${ }^{1}$ Department of Plastic and Reconstructive Surgery, Max Hospital, \\ Patparganj, Delhi, India \\ 2Department of Plastic and Reconstructive Surgery, PGIMER, \\ Chandigarh, India
}

\begin{abstract}
Address for correspondence Saleem Abid, MBBS, MS. Mch, Flat no. 101, Azad Apartments IP extension, Patparganj, Delhi 110092, India (e-mail: abidsaleem10@gmail.com).
\end{abstract}

Indian J Plast Surg 2019;52:309-313

\begin{abstract}
Introduction Based on the level of the thumb loss, phalangization, toe-to-thumb transfer, pollicization, and distraction callotasis of the first metacarpal are the various options available for reconstruction. The aims of the study were to observe the length gained in the distraction process, duration of treatment required, functional recovery in the form of pinch strength, sensations, and patient satisfaction.

Patients and Methods It was a prospective study of 10 patients of thumb amputation, conducted from January 2014 to July 2015. The patients' age, mode of injury, level of amputation, and advantages and disadvantages of distraction callotasis were evaluated.

Results The most common etiology of thumb loss was domestic accidents while working with a chaff cutter. The total duration of treatment was 124 (93-165) days and the mean gain in length was $25(20-28) \mathrm{mm}$. The pinch strength increased from a mean

Keywords

- thumb amputation

- distraction

- callotasis

- phalangization

- pollicization of 0.91 to $2.06 \mathrm{~kg}$, i.e., a $44.17 \%$ improvement from preoperative pinch strength. All of our patients retained their sensations of the reconstructed thumb post distraction. Conclusions Among many options for thumb reconstruction, distraction callotasis is a simple and safer option in the selective group of patients who are not keen on toe-to-thumb transfer which provide a significant improvement. The longer duration of treatment is the disadvantage associated with the need for proper counselling beforehand.
\end{abstract}

\section{Introduction}

The thumb in the human hand represents is the most important digit because of its opposition ability and the fact that it accounts for 40 to $50 \%$ of hand disability following its loss..$^{1-3}$ Depending on the level of amputation, different management options are available, of which distraction lengthening is old and timetested method. Matev was the first to introduce the lengthening of digits by the distraction technique for the hand. ${ }^{4}$ Since then, the application of distraction histogenesis for increasing the functional length of a skeletally deficient hand has gone through an evolution in both technique and technology. ${ }^{5-9}$

This study is our experience of distraction lengthening of the first metacarpal among selected patients of traumatic thumb amputations. Amputations at the level of interphalangeal (IP) joint or distal to it may not require reconstruction as

received

June 27, 2019

accepted after revision

July 19, 2019

published online

December 26, 2019 patients compensate for the lost length. Patients with amputations at the level of metacarpal head or metacarpophalangeal (MCP) joint or amputations up to the middle of the proximal phalanx usually need reconstruction, which can range from simple procedures such as phalangization to complex ones like toe transfer. After being provided with multiple options, those patients who opted for distraction lengthening were selected for the study. The main aim was to observe the functional improvement and length gained.

\section{Patients and Methods}

Over a period of 19 months, we operated on 10 patients who presented after traumatic amputation of the thumb. Only those patients were considered for distraction who did not give their consent for other preferred methods of thumb reconstruction C2 2019 Association of Plastic
Surgeons of India
License terms

(요 (1) $\odot \circledast$
$10.1055 / \mathrm{s}-0039-3400203$

ISSN 0970-0358. 
(including toe-to-thumb transfer). Eight patients were men and the mean age of patients at the time of distraction was 30 years (16-42). Half of our patients (50\%) met with amputation while working with a chaff cutter (Toka machine) and $40 \%$ of the patients suffered amputation while working with machines (industrial accidents). The right hand was involved in seven patients and the left hand in two patients. Only one patient presented with involvement of both hands. There were associated injuries of other fingers among four patients, with amputation of the ipsilateral index finger in three patients. On-top plasty was not conducted as amputation occurred at the MCP joint/metacarpal level.

Five of our patients had amputation at the MCP joint and four patients at the base of proximal phalanx. One patient had amputation at the level of head of the first metacarpal. The preoperative clinical assessment of the patients included documentation of pain, light touch sensation, two-point discrimination (2PD), and pinch strength measurement with adjacent finger. Pinch strength was measured using the hydraulic pinch dynamometer.

Consent was taken from all patients following guidelines setup by ICMR (1994) and the Helsinki declaration (modified 2000).

Surgical technique: The procedure was performed under general or regional block anesthesia. A 1- to 1.5-cm dorsolateral incision was made and subcutaneous tissue was divided in line with the skin incision. Blunt dissection was carried out to spread, divide, and protect important soft tissue structures; the extensor tendon was retracted toward the midline to clear off the periosteum. Two minifixator (1.5-2.5 mm self-tapping Schanz) pins were then placed with a hand drill distal to the growth plate. Subsequently, two similar pins were placed in the distal portion of the bone approximately 8 to $10 \mathrm{~mm}$ proximal to the metacarpal head, corresponding to the openings in the mini-fixator. An osteotomy was then performed with a 2 or $3 \mathrm{~mm}$ osteotome. The preferable site of osteotomy is the middle of diaphysis. A unilateral, uniaxial and uniplanar dynamic mini external fixator was assembled and attached to the pins. Intraoperative distraction was carry out for $4 \mathrm{~mm}$ to check the functioning of distractor, and a gap of $0.5 \mathrm{~mm}$ was kept between the two osteotomy ends before skin and soft tissue closure in layers. A 0.5-mm Kirschner wire was passed across the MCP joint to prevent progressive flexion contracture in case of patients with amputation at the proximal phalanx level.
After a latent period of about 5 to 7 days, distraction was begun at a rate of $0.5 \mathrm{~mm}$ to $1 \mathrm{~mm}$ per day, and in increments of $0.25 \mathrm{~mm} / 0.50 \mathrm{~mm}$ in the morning and $0.25 \mathrm{~mm} / 0.50 \mathrm{~mm}$ in the evening; this was explained to the patient/attendant.

Follow up: During distraction, patients were followed up on a biweekly basis. Sutures were removed after 10 days. After completion of distraction, a digital X-ray was repeated for documentation of the same. The device was kept in place during the consolidation phase for a period of 2 days for each $1 \mathrm{~mm}$ of distraction (50-60 days). The patients were kept on follow up and were assessed after every 4 weeks.

After the completion of the consolidation phase, the quality of bone regenerate was assessed through digital X-ray. The mini-external fixator was removed after ensuring adequate bone regenerate. The patients were reviewed 1 to 2 weeks after the fixator removal for assessment of outcome parameters, i.e., length gained and the functional assessment of distracted thumb; till that period, the patients were kept on a thumb Spica splint (-Figs. 1 to 3 ).

\section{Results}

Nine of our patients completed the treatment and follow-up. In one patient, we had to abandon distraction after about 3 weeks in view of severe pin tract infection and no response to antibiotics. The distractor was removed and osteoplastic thumb reconstruction was conducted at a later date. The post-distraction assessment was carried out with respect to duration of treatment, gain in length, sensory and functional assessment (- Table $\mathbf{1}$ ).

The mean time of distraction was 39.77 days, and the consolidation phase was nearly double of that of the distraction phase at a mean of 84.66 days. On average, the total duration of treatment was approximately 124.44 days/patient. Also, the mean gain in length was $25.33 \mathrm{~mm}$ (range of 20-28 mm), which constituted an average increase of $26.6 \%$ length in each case (-Table 2 ).

Pin prick sensations and light touch were checked over the pulp of the involved thumb and it showed no significant change. Two patients recorded a score of 1 and 7 patients registered a score of 2 .

Also, there was no significant change in $2 \mathrm{PD}$, over the pulp of thumb, before and after distraction $(p=0.548)$. Thus, all of our patients had retained their sensibility before and
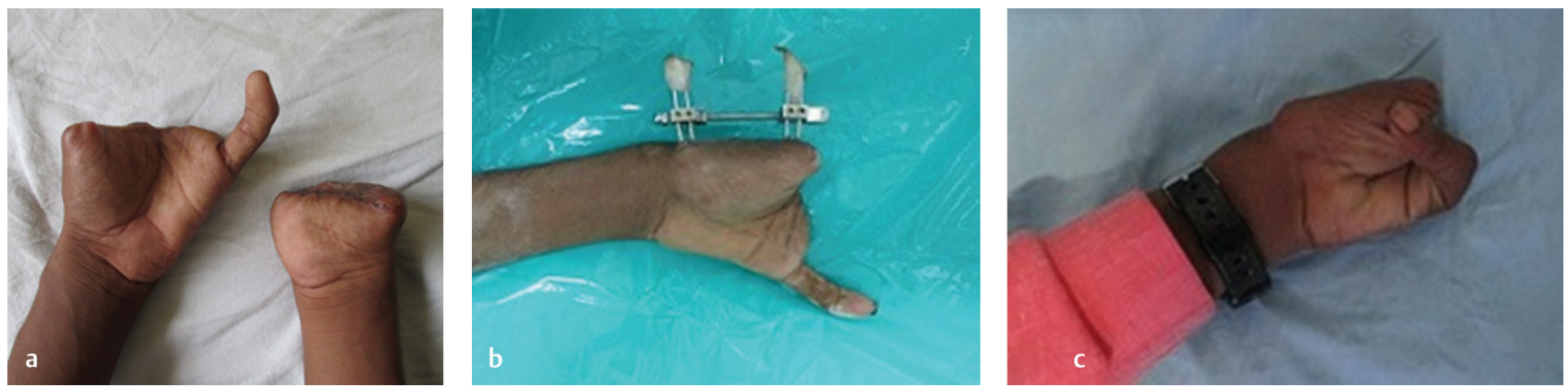

Fig. 1 (a) Case 1: Patient with involvement of both hands while working with chaff cutter. (b) Case 1: Patient during distraction phase. (c) Case 1: Picture postdistraction, patient able to oppose little finger with reconstructed thumb. 

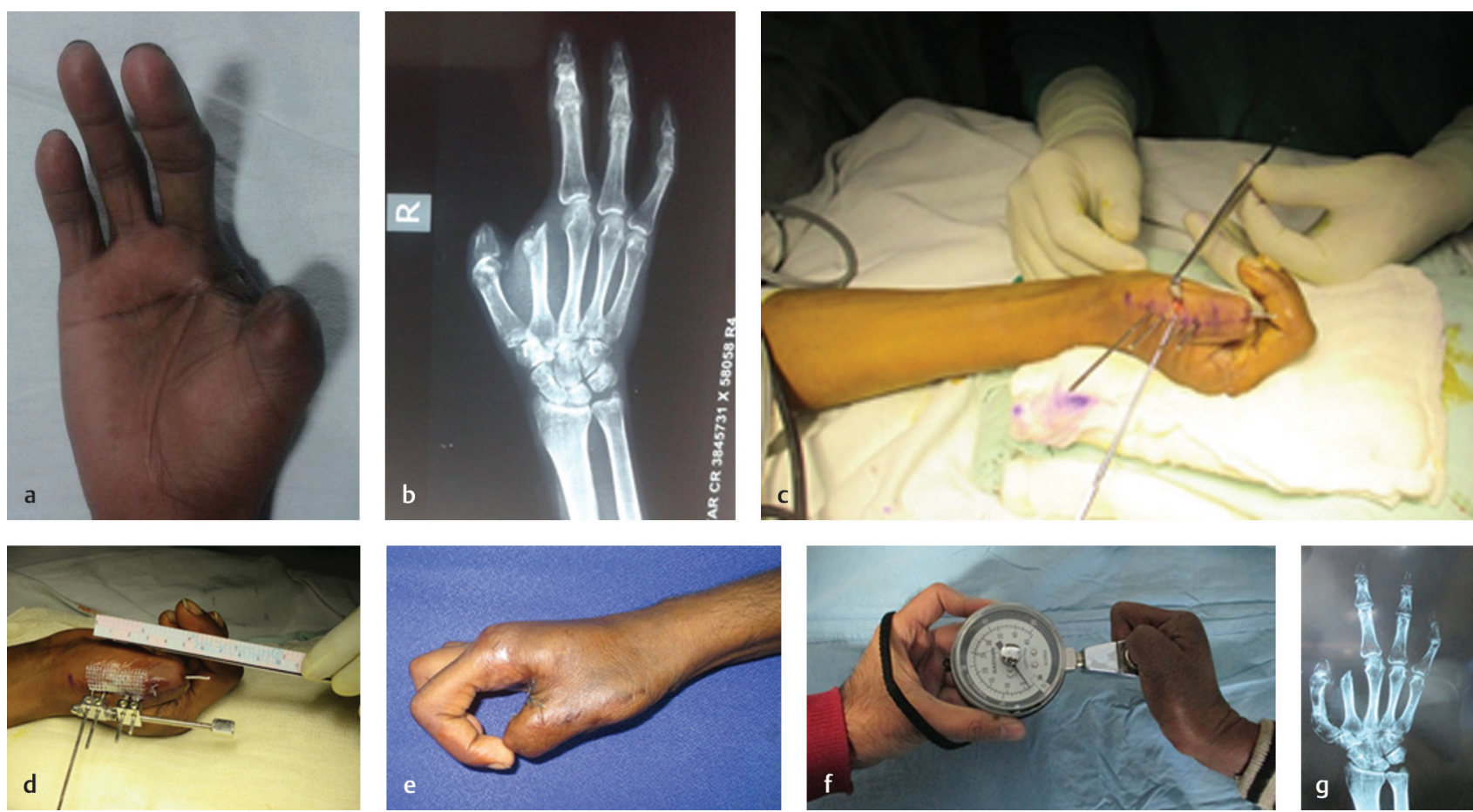

Fig. 2 (a) Case 2: Pre-op picture with amputation of thumb and index finger. (b) Case 2: Pre-op X-ray with amputation of thumb and index finger. (c) Case 2: Intra-op picture showing osteotomy and insertion of Schanz pins. (d) Case 2: Immediate post-op picture showing mini fixator in place. (e) Case 2: Post-op picture showing lengthened thumb with good opposition ability; this was observed post webplasty. Volar bending of metacarpal is noticed. (f) Case 2: Pinch strength measurement by hydraulic pinch dynamometer. (g) Case 2: Postdistraction, X-ray lengthened thumb metacarpal with slight volar bending can be noticed.
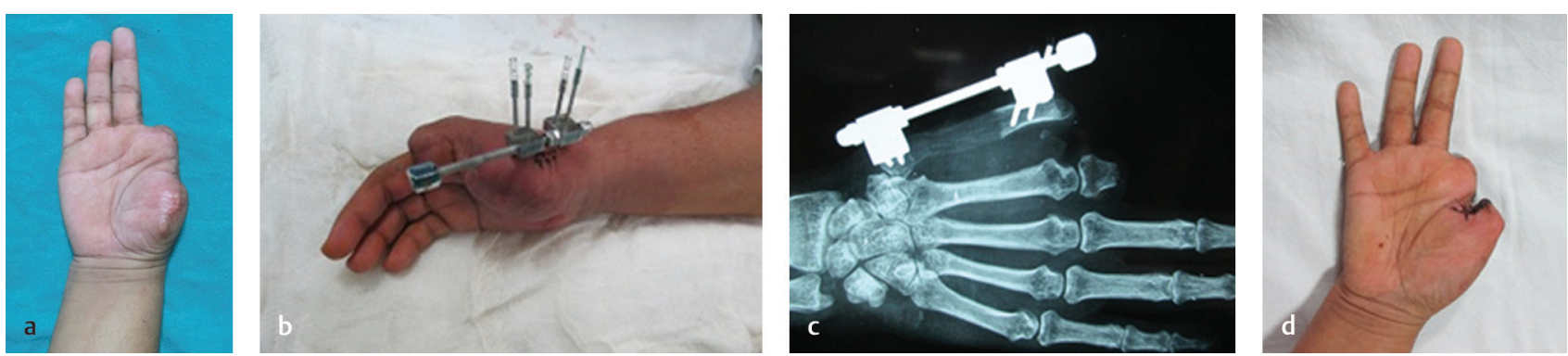

Fig. 3 (a) Case 3: Amputation of thumb and index finger. (b) Case 3: Immediate post-op picture showing minifixator in place. (c) Case 3: X-ray in postdistraction period showing callus formation. (d) Case 3: Post-op picture showing lengthened thumb post webplasty.

Table 1 Patient characteristics and post distraction changes

\begin{tabular}{|c|c|c|c|c|c|c|c|c|}
\hline SI. no. & $\begin{array}{l}\text { Age } \\
\text { (y) }\end{array}$ & $\begin{array}{l}\text { Level of } \\
\text { amputation }\end{array}$ & $\begin{array}{l}\text { Pre-op length } \\
(\mathrm{cm})\end{array}$ & $\begin{array}{l}\text { Post-op } \\
\text { length } \\
(\mathrm{cm})\end{array}$ & $\begin{array}{l}\text { Duration of } \\
\text { distraction (d) }\end{array}$ & $\begin{array}{l}\text { Duration of } \\
\text { consolidation } \\
\text { (d) }\end{array}$ & $\begin{array}{l}\text { Pinch } \\
\text { strength } \\
\text { (kg) pre-op }\end{array}$ & $\begin{array}{l}\text { Pinch strength } \\
\text { (kg) post-op }\end{array}$ \\
\hline 1 & 19 & MCP joint & 58 & 84 & 43 & 85 & 2.7 & 3.6 \\
\hline 2 & 29 & Base of PPX & 65 & 87 & 31 & 62 & 0 & 1 \\
\hline 3 & 16 & $\begin{array}{l}\text { Proximal to } \\
\text { MCP joint }\end{array}$ & 40 & 60 & 32 & 70 & 0 & 0 \\
\hline 4 & 38 & MCP joint & 50 & 78 & 44 & 90 & 0 & 1.5 \\
\hline 5 & 28 & MCP joint & 60 & 84 & 35 & 75 & 0 & 2 \\
\hline 6 & 38 & Base of PPX & 63 & 90 & 46 & 98 & 2 & 3 \\
\hline 7 & 41 & MCP joint & 61 & 89 & 34 & 77 & 1 & 2.5 \\
\hline 8 & 34 & MCP joint & 59 & 86 & 41 & 92 & 1.5 & 3 \\
\hline 9 & 42 & Base of PPX & 62 & 88 & 52 & 113 & 1 & 2 \\
\hline 10 & 23 & Base of PPX & 52 & 52 & \multicolumn{4}{|c|}{$\begin{array}{l}\text { Distraction stopped in view of pin tract infection and patient excluded } \\
\text { from the study }\end{array}$} \\
\hline
\end{tabular}


Table 2 Mean gain in length

\begin{tabular}{|l|l|l|l|}
\hline & Mean $(\mathrm{mm})$ & $N$ & Standard deviation \\
\hline Preoperative length & 57.556 & 9 & 7.8280 \\
\hline Postoperative length & 82.889 & 9 & 9.2931 \\
\hline
\end{tabular}

after distraction and there were no neurovascular problems encountered. The functional improvement was noticed among 8 patients, with improvement in mean pinch power, which increased from a mean of 0.91 to $2.06 \mathrm{~kg}$, i.e., $44.17 \%$ improvement from preoperative pinch strength.

\section{Discussion}

Traumatic amputation of the thumb is one of the worst consequences one's hand will ever suffer. One loses 40 to 50\% of hand function after thumb amputation..$^{1-3}$ Multiple reconstructive options are available, depending on the patient's age, sex, profession of patient, level of amputation, patient preferences, and surgical skill of surgeon.

The commonly used procedures for thumb reconstruction are re-implantation, whenever possible, toe-to-thumb transfer, pollicization, on-top plasty, osteoplastic thumb reconstruction, phalangization techniques, and distraction callotasis of the first metacarpal. Toe-to-thumb transfer is the preferred procedure for thumb amputations, but it is a technically challenging procedure and requires sacrifice of the second toe, which most patients in our part of the country refuse to give consent for due to cosmetic reasons, social barriers, and the fear of losing the grip while wearing footwear. Considering pollicization for thumb reconstruction, a surgeon should be well-versed with the procedure, as it is a technically demanding procedure and may lead to weak power grip. Motivating a patient for pollicization is another hurdle, as many patients are reluctant to sacrifice their index finger.

On-top plasty is an option among patients having multiple digit amputations. Transfer of a part of another digit to the thumb will depend upon the level of amputation of the donor digit. Disadvantages may be reduced grasp strength and palm span. Osteoplastic thumb reconstruction is a staged procedure using a bone graft and a soft tissue flap to cover it. Although it is a relatively rapid method of thumb reconstruction, its disadvantages include an insensate thumb, poor cosmetic appearance and the loss of a flap or bone graft.

Distraction callotasis presents a unique clinical tissue engineering technique which was first reported by Codvilla in $1905 . .^{10}$ The technique is unique in that it applies gradual and incremental traction, and releases inherent biological forces to generate human tissues that are bone and associated neurovascular and soft tissue complex. ${ }^{11}$ It provides adequate length, making use of native tissues, lengthens soft tissues gradually without any neurovascular compromise, and gives one a sensate thumb when there are no donor site morbidity issues.

The utilization of distraction callotasis in hand was first descried by Matev IB in 1970, when he presented 3 patients of thumb amputation who were treated by distraction lengthening. In their series, most of the adult patients required bone graft to fill the gap between the osteotomy sites due to slow rate of callus formation. Therefore, they recommended that a gap of $3 \mathrm{~cm}$ or more should be filled with corticocancellous bone graft, more so in patients who are over 20 years of age because of doubtful spontaneous consolidation. Most authors have followed this advice ${ }^{2,12-15}$

Later, many authors came up with their experience by keeping the distractor in situ till complete consolidation of newly formed callus without using any bone graft, as that required another surgery, besides having donor site morbidity. $6,8,16,17$ We also followed the identical procedure and obtained good measure of thumb length by gradual and incremental distraction without using bone graft. We started distraction after 5 to 7 days of surgery and it was performed at an average of $0.63 \mathrm{~mm}$ per day. The mean time of distraction was 39.77 days and total duration, including consolidation phase, was 124 days. Most of the authors similarly start distraction from 4 to 7 days after surgery. ${ }^{8,18,19}$ Robert Zimmermann in his study of 10 patients began distraction on the 7 th day and at a rate of $1 \mathrm{~mm}$ per day. ${ }^{20}$ Matev, in his experience of 20 years, started distracting within three to four days after surgery at a daily rate of 7 to $7.5 \mathrm{~mm}$. His total duration of treatment was three to four months when bone graft was not used and 2 to $3 \mathrm{~cm}$ of elongation was readily achieved. $^{21}$

Roberto Adani et al completed distraction in approximately 65 days and were able to achieve a length of $23 \mathrm{~mm} .{ }^{19}$ We obtained almost similar results, achieving a mean length of $25.33 \mathrm{~mm}$ (range of $20-28 \mathrm{~mm}$ ). Komurcu et al performed distraction callotasis of thumb in 12 patients and achieved a mean length of $28.9 \mathrm{~mm} .{ }^{22}$ Finsen and Russwurm conducted distraction over a median of 66 days (28 to 109 days) after osteotomy, resulting in a median lengthening of $30 \mathrm{~mm}$ $(17-36 \mathrm{~mm})$, which is more than what we achieved but they achieved it at the cost of a long period of treatment and follow-up that totaled 326 days (140-489 days). ${ }^{6}$ Our patients had distractor in situ for a mean of 124.44 days after which patients were able to return to their daily routine. Two of our patients, whose nondominant hand was involved, returned to their workplace after 2 weeks of distractor placement. Six patients later required webplasty but that was carried out as part of day-care procedure without the need for admission. Deepening of first web space is a practice followed by many other authors as well. Toh et al performed Z-plasty to deepen the first web in four of their patients who had developed adduction contracture. ${ }^{16}$

Sensation was retained in all thumbs with non-significant change in pin prick sensation, light touch sensation and 2PD. One patient was initially managed with the help of a groin flap cover to the amputated stump. The flap was covering the dorsum of thumb and his volar skin was intact. His volar skin sensation score was 2 but only deep 
pressure sensation was present over the dorsum of the stump. Houshian and Ipsen also found that all of their patients possessed normal sensibility before and after distraction and neurovascular problems were not encountered. ${ }^{18}$ Finsen and Russwurm found that 2PD on the pulp of the reconstructed thumb was $8 \mathrm{~mm}(5-9 \mathrm{~mm})$ compared with $4 \mathrm{~mm}$ (3-5 $\mathrm{mm})$ on the pulp and $6 \mathrm{~mm}(4-9)$ on the volar skin over the MCP joint on the uninjured side. ${ }^{6}$ We did not find a significant difference between the 2PD of uninjured and injured thumb (3.61 and 5.55) over the pulp.

Toh et al achieved a mean pinch power of $6.8 \mathrm{~kg}$ (4.8-10.1 kg) in their 14 satisfied patients, which corresponds to $76 \%$ of that of the contralateral hand. ${ }^{16}$ Houshian and Ipsen also achieved pinch strength of $86 \%$ (range of $66-100 \%$ ) in the normal hand. ${ }^{18}$ We believe that the reason for less gain of pinch strength $(44.17 \%)$ in our patients was the associated injuries in four of our patients and the low pinch strength before going in for surgery ( $0.91 \mathrm{~kg}$ only). Three patients had also lost their index fingers during the primary insult. One patient had lost index finger only, another patient index and distal phalanx of middle finger, and third patient had lost index, middle and ring finger. Therefore, due to absence of a stable post against thumb, these patients could not improve much of their pinch power after distraction.

Thus, we suggest distraction callotasis as a method of thumb reconstruction among a selected group of patients wherein amputation is at the level of MCP joint or proximal phalanx, although toe-to-thumb transfer, on-top plasty and pollicization are better options wherever possible

\section{Key Messages}

Thumb amputations are common injuries among farmers and industrial laborers. The options of reconstruction should be simple and safe; aesthesis is not the priority in these patients. Thumb lengthening by distraction, besides being safe and simple, preserves the sensations and improves pinch strength.

\section{Source(s) of Support}

None.

\section{Presentation at a Meeting}

Organization: North Zone Association of Plastic Surgeons of India; place: Srinagar; date: October 2017.

\section{Conflict of Interest}

None.

\section{Acknowledgments}

We acknowledge the support of all the consultants of plastic surgery at PGI Chandigarh, as well as the support and cooperation of all our patients.

\section{References}

1 Beasley RW. Surgery of hand and finger amputations. Orthop Clin North Am 1981;12(4):763-803

2 Moy OJ, Peimer CA, Sherwin FS. Reconstruction of traumatic or congenital amputation of the thumb by distraction-lengthening. Hand Clin 1992;8(1):57-62
3 Reigstad A, Hetland KR, Waage S, Bye K, Røkkum M. Transfer of the second toe for reconstruction of the hand after trauma. Scand J Plast Reconstr Surg Hand Surg 1992;26(1):105-110

4 Matev IB. Thumb reconstruction after amputation at the metacarpo-phalangeal joint by bone lengthening: a preliminary report of three cases. J Bone joint Surg 1970;52-A:957-965

5 Seitz WH, Jr, Shimko P, Patterson RW. Long-term results of callus distraction-lengthening in the hand and upper extremity for traumatic and congenital skeletal deficiencies. J Bone Joint Surg Am 2010;92(Suppl 2):47-58

6 Finsen V. Russ worm. Metacarpal lengthening after traumatic amputation of the thumb. J Bone and Joint Surg 1996;78B:133-136

7 Joist A, Neuber M, Frebel T, Joosten U. [Callus distraction of the first metacarpal bone for thumb reconstruction after traumatic amputation]. Unfallchirurg 2000;103(12):1073-1078

8 Heitmann C, Levin LS. Distraction lengthening of thumb metacarpal. J Hand Surg [Br] 2004;29(1):71-75

9 Das SP, Mohanty RN, Das SK. Metacarpal lengthening by distraction histiogenesis in adults. Indian J Orthop 2009;43(4):379-382

10 Codvilla A. On the means of lengthening in the lower limbs, the muscles and tissues which are shortened through deformity. Am J Orthop Surg (Phila Pa) 1905;2:353

11 Mc Carthy GJ. Principles of craniofacial distraction. In: Thorpe $\mathrm{CH}$ ed. Grab and Smith's Plastic Surgery 6th ed. Wolters Kluwer; 2007 96-102

12 Burkhalter W. Mutilating injuries of the hand. Hand Clin 1986;2(1):45-68

13 Kanaujia RR, Fukuhara C, Yoshioka K, Miyamoto Y, Hoo KI. Experience with Ikuta's phalangeal compression-distraction-fixation device. J Hand Surg Am 1988;13(4):515-521

14 Cobb TK, Stocks GW, May WF. Strauss MR, Lewis RC Jr. Thumb reconstruction by metacarpal lengthening after traumatic loss at the level of the interphalangeal joint. Orthop Rev 1990;19(1):47-51

15 Hette K, Lemke T, Knaepler H. Distraction of the first metacarpal bone for thumb reconstruction [in German]. Unfallchirurg 1992;95(6):294-297

16 Toh S, Narita S, Arai K, Nakashima K, Tsubo K. Distraction lengthening by callotasis in the hand. J Bone Joint Surg Br 2002;84(2):205-210

17 Preisser P, Rudolf K, Partecke BD. Reconstruction of thumb through continuous lengthening of the first metacarpus [in German]. Oper Orthop Traumatol 1997;9(2):150-161

18 Houshian S, Ipsen T. Metacarpal and phalangeal lengthening by callus distraction. J Hand Surg [Br] 2001;26(1):13-16

19 Adani R, Corain M, Tarallo L, Fiacchi F. Alternative method for thumb reconstruction. Combination of 2 techniques: metacarpal lengthening and mini wraparound transfer. J Hand Surg Am 2013;38(5):1006-1011

20 Zimmermann R. Reconstruction of amputated thumb through lengthening of first metacarpal. Orthop Traumatol 2002;10(4):258-267

21 Matev IB. The bone-lengthening method in hand reconstruction: twenty years' experience. J Hand Surg Am 1989;14(2 Pt 2) :376-378

22 Kömürcü M, Kürklü M, Demiralp B, Atesalp AS, Alsancak S, Basbozkurt M. First ray reconstruction with distraction osteogenesis. Prosthet Orthot Int 2008;32(1):50-56 